\title{
DOCUMENTARTE \\ Encontro com documentos e pensamento professoral no ensino de História $^{*}$
}

\author{
Luciane Helbich ${ }^{1}$ \\ Nilton Mullet Pereira ${ }^{2}$
}

Resumo: Este é um trabalho com um perfil histórico-filosófico. Procura discutir os conceitos de pensamento e de encontro, a partir da relação entre o professor de História e os documentos, e tendo como fontes de inspiração Deleuze, Foucault e Spinoza. Nesse sentido, compreende a criação de narrativas como o momento privilegiado da prática professoral, na Escola Básica, revelando-se como um processo que decorre de uma violência do pensamento, ensejado pelos encontros entre um fazer professoral e os documentos históricos. O ofício do professor de História é considerado como um fazer artístico e gerador de histórias-problema. Nesta perspectiva, as narrativas pensadas a partir do encontro do professor com os documentos são apresentadas como um movimento de imaginação criativa. Procura-se lançar novos olhares sobre as experiências com os documentos e entendê-las como atualização de virtualidades que a potência dos documentos disponibiliza. Pensando a partir da filosofia da diferença, este texto busca a empiria com a matéria de expressão, que são os documentos que dão consistência à criação de um novo plano de pensamento.

Palavras-chave: Pensamento; Ensino de História; Produção de narrativas.

\begin{abstract}
This is a paper with a historical-philosophical profile. It discusses the concepts of thought and encounter, starting from the relationship between the History teacher and documents, having as sources of inspiration Deleuze, Foucault, and Spinoza. In this sense, it includes the creation of narratives as a privileged moment of teaching in Elementary School, revealing itself as a process that comes from a violence of thought, brought on by encounters between a teacher's work and historical documents. The work of a History teacher is considered as artistic and generates problem-histories. In this perspective, the narratives designed from the meeting of the teacher with the documents are presented as a movement of creative imagination. Seeking ways to launch new insights on experiences with the documents and understanding these experiences as updated virtualities which the power of the documents make available. Starting from the philosophy of difference, this paper seeks the empirical with matters of expression, which are those documents that give the consistency necessary to create a new plan of thought.
\end{abstract}

\footnotetext{
* Artigo submetido em 20 de outubro/2012 e aceito para publicação em 08 de julho/2013.

${ }^{1}$ Professora da Escola Básica. Licenciada em História e Mestre em Educação (UFRGS).

Email: lucianehelbich@gmail.com

${ }^{2}$ Professor da área de Ensino de História, da Faculdade de Educação, da UFRGS. Licenciado em História (UFRGS) e doutorado em Educação (UFRGS). Pós-doutorado em Estudos Medievais. Email: 00039576@ufrgs.br
}

Em Tempo de Histórias

Publicação do Programa de Pós-Graduação em História da Universidade de Brasília (PPGHIS/UnB)

No. 23, Brasília, ago. - dez. 2013

ISSN 2316-1191 
Keywords: Thought; Teaching History; Production of narratives.

Lucien Febvre afirmava, em 1949, que a história se faz com documentos escritos, mas na ausência destes, o historiador pode se utilizar das

palavras. Signos. Paisagens e telhas, com as formas do campo e das ervas daninhas. Com os eclipses da lua e a atrelagem dos cavalos de tiro. Com os exames de pedras feitos pelos geólogos e com as análises de metais feitas pelos químicos. Numa palavra, com tudo o que, pertencendo ao homem, depende do homem, serve o homem, exprime o homem, demonstra a presença, a atividade, os gostos e as maneiras de ser do homem (Febvre apud LE GOFF, 1992: 540).

Desde então, não apenas reafirma-se o papel do documento na escrita da História, como se revoluciona a definição qualitativa do que consiste o documento histórico. $^{3}$

Os documentos se constituem na matéria de expressão da escrita da História e da composição da narrativa. Essa verdadeira revolução se faz sentir igualmente no ensino de História onde os documentos, por força da pesquisa e da legislação, se tornam parte indispensável da aula de História, constituindo-se também em matéria de expressão do ensino. Ou seja, a massa documental é vista, deste lugar de onde escrevemos, como a matéria que serve para produzir sentidos - trata-se antes de tudo de permitir a criação em História, para servir de matéria a partir da qual o professor pensa. Eis que o pensamento é o objetivo do contato entre a prática professoral e sua matéria de expressão, os documentos.

Os PCN salientam o trabalho com fontes históricas, enfatizando o caráter diverso e a riqueza da massa documental à disposição do Historiador e do ensino, considerando a necessidade da utilização de outras fontes documentais que não as fontes

\footnotetext{
${ }^{3} \mathrm{O}$ conceito de documento é uma escolha neste texto. Tal conceito é amplamente discutido no meio historiográfico e, inclusive, adquiriu ao longo do século XX outras nomenclaturas como fonte, vestígio e monumento. Escolher a palavra documento partiu das leituras de Jacques Le Goff (História e Memória) e Michel Foucault (Arqueologia do Saber) onde os autores problematizam o conceito conferindo a ele o sentido de monumento. Apesar de partir destas referências, o conceito aqui apresentado parte em busca de outra definição que se experimenta construir aproximando-se da arte e da filosofia: Documentarte.
}

Em Tempo de Histórias

Publicação do Programa de Pós-Graduação em História da Universidade de Brasília (PPGHIS/UnB)

No. 23, Brasília, ago. - dez. 2013

ISSN 2316-1191 
escritas. ${ }^{4}$ Nesse sentido, para o Ensino Médio, por exemplo, sugere-se a necessidade da análise e interpretação de testemunhos e fontes históricas, do passado e do presente, demonstrando o papel que assume o uso do documento em sala de aula.

No campo da pesquisa, o ensino de História vem sendo constantemente problematizado e o uso de documentos está entre os elementos que se mostram à análise e à investigação. $\mathrm{O}$ trabalho de Bittencourt se dedica a tratar das diversas nuances do ensino de História, mas especifica que a utilização do documento em sala de aula tem ampliado às possibilidades de crítica por parte dos alunos e servido para introduzir o método histórico no interior da sala de aula (Cf. BITTENCOURT, 2004). Mais recentemente pode-se citar o trabalho de Schmidt e Cainelli, que se preocupam em dar conta, na perspectiva da Educação histórica, das diversas formas expressivas do ensino de História, num estudo que, igualmente, salienta que a fonte histórica pode ser um modo de elevar os parâmetros da consciência histórica dos jovens (Cf. SCHIMIDT, \& CAINELLI, 2004). Por fim, vale a pena citar o trabalho de Pereira e Seffner (2009), que abordam o documento, considerando-o como um modo de demonstrar aos estudantes a complexidade da construção do conhecimento histórico, fornecendo elementos para a compreensão da própria historicidade da História e do ensino de História.

Este artigo quer inserir-se nessa discussão sobre o documento e sua relação com o ensino de História. Nosso objetivo é problematizar filosoficamente o pensar do professor de História da escola básica, no sentido de apreender o movimento expressivo e de pensamento que o encontro com os documentos pode permitir ao professor.

Logo, é um artigo sobre uma filosofia do ensino de História; que aborda a matéria de expressão que são os documentos e trabalha com os encontros, com as afecções que os vestígios do passado podem permitir quando os professores de História com eles se encontram. Trata-se de uma filosofia do encontro e da afecção. Trata-se ainda de um movimento de pensamento, revelado no interstício, na fenda, entre os corpos de professores e de documentos.

\footnotetext{
${ }^{4}$ Cf. Parâmetros Curriculares Nacionais - Ensino Médio. Ministério da Educação. 2000. Pesquisado em 20 de agosto de 2012. http://portal.mec.gov.br/seb/arquivos/pdf/blegais.pdf

Em Tempo de Histórias

Publicação do Programa de Pós-Graduação em História da Universidade de Brasília (PPGHIS/UnB)

No. 23, Brasília, ago. - dez. 2013

ISSN 2316-1191
} 
O documento, já pensado como evidência ou comprovação de um passado que se afirma ter existido, também foi tomado como monumento de sociedades que buscaram se constituir e salvaguardar determinada imagem de si próprias. Tais concepções de abordagem do documento histórico percorreram o século XX e talvez ainda continuem a sustentar o uso de documentos nas salas de aula de História.

Queremos neste artigo seguir esse mesmo caminho, mas procurar andar por outras vias, na medida em que o documento é aqui tratado como obra de arte a se encontrar com o professor de história. O documento, assim, se desloca das concepções e metodologias específicas já construídas e legitimadas pelo conhecimento histórico e adquire uma outra conceituação que o entende como monumento artístico a se compor com o corpo a encontrá-lo.

\section{Pensamento e ensino de História}

Nesta produção, o pensamento é problematizado filosoficamente como movimento de criação e de efetuação de novos modos de vida. Como prática livre, o pensamento não se enquadra em modelos representativos já constituídos. Pelo contrário, aqui o pensamento é exercício decorrente dos efeitos dos encontros da vida e busca ultrapassar as velhas significações que o campo social e epistemológico lhe impõe. Busca respirar o ar da arte como produção de diferentes formas de vida e escolhe como prática estética de existência a composição de forças que se misturam bem com seu corpo e que lhe tragam novos sentidos.

Pensar se dá através da violência. Da violência de um encontro que ultrapassa os limites do que há, do que é, do que passa. Pensar é instalar-se de súbito numa região onde nada ainda é formado, onde habitam singularidades selvagens que se movimentam sem cessar. Trata-se de uma espécie de não-lugar, onde apenas há forças que se chocam umas nas outras - uma espécie de essência do real, puro movimento, pura mutação, puro tempo. A esse não-lugar Blanchot deu nome de Fora e Michel Foucault (2009) elabora a noção de um pensamento do exterior ou de um pensamento de-Fora. 
O Fora está numa relação imanente e a priori com os estratos, os saberes, às formas já constituídas e já sedimentadas que formam o plano sobre o qual elaboramos nosso cotidiano, mas, pensar é, justamente, ao abrir-se para o Fora, ultrapassar a linha do cotidiano. Pensar é ultrapassar a linha. A linha do saber, como lugar de posições já definidas de sujeito, como estratos onde se formaram objetos; ultrapassar a própria linha do poder, que constitui um processo de subjetivação baseado em técnicas coercitivas. Justo porque o pensamento se forma quando um Fora se dobra e se interioriza, no sentido em que pensar é dobrar o fora e constituir um interior; uma subjetividade; um eu; uma memória; uma duração (Cf. DELEUZE, 1999). Trata-se, portanto, de uma experiência consigo, mas não ao modo do saber, nem do poder, mas da relação com esse espaço onde não há saber, nem práticas coercitivas, senão que um turbilhão caótico de inimagináveis, de impossibilidades, onde o pensamento se encontra com a própria impossibilidade de pensar. A dobra do Fora para dentro, eis o processo pela qual se constitui um caos dentro de cada um. Ou seja, a dobra da subjetivação é o que cria uma desaceleração do Fora, mas ao mesmo tempo uma abertura. Uma desaceleração que permite suportar a avalanche de forças que se inserem por dentre os interstícios do ver e do falar, das formas do saber; uma abertura para deixar entrar as forças, para com elas produzir novidades, fazendo ultrapassar a linha, desidentificar o cotidiano, criar novas máscaras para continuar a viver.

Um gargalo semi-obstruído filtra, desacelera, curva, rejeita, amortece, seleciona as forças do Fora, mas ao mesmo tempo constitui uma passagem, via de comunicação, de permeabilidade etc. O que Foucault estaria sugerindo, então, é que, para que o Outro, o Fora, o mais longínquo se torne a intimidade do pensador, seria preciso desobstruir ao máximo o gargalo da zona de subjetivação em direção ao Fora (PELBART, 1989, p. 137).

Desobstruir o gargalo é perturbar a percepção, colocar-se num salto prá fora do presente vivido, para além do limite das formas e deixar-se abater pelo impensado. Assim, esse Fora longínquo se torna íntimo, constitui uma interioridade, cria uma sufocante neutralidade no interior, de modo que ela, ainda em estado de préindividuação, sem moral, sem constituição do verdadeiro e do falso, possa dar espaço ao impulso vital, para deixar fluir a diferença.

Em Tempo de Histórias

Publicação do Programa de Pós-Graduação em História da Universidade de Brasília (PPGHIS/UnB)

No. 23, Brasília, ago. - dez. 2013

ISSN 2316-1191 
Pensar é, então, expor-se ao labirinto. Fugir do presente e negar a sucessão e a continuidade. O si mesmo é a memória, diz Deleuze (1988), uma vez que é o si mesmo que, na experiência que dura, deixa antever o impulso que é vida, que é pura diferença e que deixa as singularidades selvagens que habitam o Fora, numa força de atualização, criem novos presentes, estabeleçam novas configurações do saber, das formas do saber, do visível e do enunciável. Pensar é expor-se ao labirinto porque é mesmo fugir do tempo presente, medido, ordenado, formado, constituído e controlado pela inteligência. O labirinto nos leva a um tempo sem ordem, sem medida, donde as temporalidades se interpenetram, ao invés de se sucederem na continuidade do espaço. Pensar é entrar em contato com essa dimensão onde se pode, pelo impulso de vida, numa palavra, criar. Então, se por um lado é preciso desacelerar as forças que vem de-Fora, por outro lado, é preciso manter uma abertura que permita essa intrusão desequilibradora das forças. Eis a constituição de si, eis a criação, eis o pensamento.

Uma subjetividade é sempre uma abertura e uma desaceleração. Um sujeito, constituído sob as formas do saber, é um estado de coisas existente, que nada pode oferecer de novo; um sujeito constituído pelas relações coercitivas de poder atualiza-se num estado de coisas existente, que nada de novo pode oferecer. Para que o mundo possa fluir como movimento, como devir, para que seja possível que novas atualizações constituam novos territórios, subjetividades abertas escoam no exato momento em que a força, ao invés de chocar-se com outras forças, como é seu destino, volta-se contra si mesma. A força chocando-se contra si mesma, vergada sobre si, dobrada sobre si, constituindo um interior. Um interior sempre em contato com o Fora, na medida em que a dobra lhe permite criar, cavar dentro de si um exterior, um Fora, como que um turbilhão de forças a forçar a pensar.

Para Michel Foucault tratou-se de ver no processo de subjetivação um modo de criar uma estética da existência. Um modo de constituir a si mesmo como obra de arte, como a buscar constantemente singularidades ainda não formadas, como a se deixar abrir para a entrada de tais singularidades. O si mesmo passou a ser para ele uma saída estratégica do mundo contemporâneo, uma vez que é preciso escrever a História e ensinar a História em um mundo sem Deus e sem uma razão universal. O si mesmo 
passa a ser a saída estratégica para ultrapassar a linha, para criar a novidade, para fugir ao controle, aos processos disciplinares. Michel Foucault ${ }^{5}$ estudou o cuidado de si dos gregos e compreendeu como, nas palavras de Deleuze, eles vergaram a força. Os gregos criaram o cuidado de si, constituindo a vida de uma maneira estética, criando vida como obra de arte, através de regras facultativas.

Então, se os estratos criam lugares de sujeitos produzidos, portanto num enquadramento realizado a partir do saber, do discurso; se o poder produz um sujeito como efeito das relações entre as forças, das relações de poder, num processo coercitivo, a linha da subjetivação produz, não um sujeito, mas uma subjetividade. Por que a subjetivação é sempre aberta. Uma subjetivação nunca se esgota. Então, a linha da subjetivação é a dobra da força, é a força contra ela mesma. Os gregos chamavam de agonística, a guerra de si contra si mesmo. O combate permanente contra as paixões e os excessos, com vistas ao ideal de equilíbrio, de temperança e de comedimento. De certo que o processo de liberdade era o vergamento da força contra ela mesma, um voltar-se a si, num movimento ético, que não respondia a regras exteriores. Foucault viu nos gregos esse movimento de constituição de si como produto de regras facultativas e, sobretudo, como modo de dobrar a força contra si mesma. Então, a linha de subjetivação é o que permite pensar em escapar do dispositivo. Ou o que permite pensar, uma vez que pensar é saltar fora dos dispositivos, das formações e chocar-se contra o poder.

$\mathrm{Na}$ relação consigo mesmo e na relação com os outros se produz um si, um modo específico, um jeito, um lugar. E essa produção do si é uma criação ética e estética. Portanto, é uma obra de arte. E é assim por que a linha de subjetivação pode ser sempre uma linha de fratura. Pode ser sempre uma linha que corta um dispositivo. Por que quando a força é dobrada, de onde vem a força? Do Fora. E cria um Fora no lado de dentro. O que permite esse contato permanente do Fora com o lado de dentro. E o que permite estar minimamente aberto para o Fora, não é outra coisa senão o que permite pensar. Então pensar é produzir novidade. Produzir novidade é pensar. Pensar é

\footnotetext{
${ }^{5}$ Michel Foucault abordou o tema do cuidado de si no mundo antigo nos livros sobre a história da sexualidade e em A hermenêutica do sujeito. Trad. Márcio Alves da Fonseca e Salma Tannus Muchail. São Paulo: Martins Fontes, 2004.
} 
aprender, aprender é pensar. Pensar para Foucault e para Deleuze é um exercício que se dá na relação com o Fora, não numa submissão aos estratos e às forças de um diagrama. É por isso que a linha da subjetivação pode ser sempre uma linha de resistência.

Um professor de História é também um resultado e como resultado assume uma identidade. Mas, não queremos pensar em uma identidade professor de História. Uma forma que se constitui em um jeito modelar, uma determinada maneira de se expressar e de transmitir o conhecimento histórico. Porque pensar é, como dissemos, justamente, ultrapassar a linha, a linha que forma uma identidade e como modelo de comportamento e de conduta numa realidade dada. Logo, para pensar a forma professor de história é preciso antecipar-se a ela, ir a procura dos encontros que a tornaram possível, que a atualizam constantemente em uma realidade que intervém no mundo real ao dar continuidade à produção do passado como memória. Além do mais, estamos a pensar a possibilidade do professor de História se pôr a pensar. Nesse sentido, procuramos dar conta de um estado anterior e pré-individual e examinar a criação na docência em História. É possível pensar sendo docente em História, é possível ultrapassar a linha, dobrar a força, ainda que o objetivo da aula de História tenha sido tradicionalmente o de informar sobre o passado. Mas, há uma vida professor de História, uma vida de encontros, uma vida de criação que se dá a partir das afecções que recebe da sua matéria de expressão, os documentos. Há criação no ensino de História, eis o que quer afirmar este artigo.

\section{Professor de História - encontros}

A vivência de um professor de História é perpassada por diferentes encontros. Seu ofício requer diferentes aproximações com a produção cultural humana. É um profissional do encontro, sua matéria de pensamento e aprendizagem é a obra humana. Pesquisar o pensamento e o aprendizado do professor de História, através do olhar filosófico da Diferença, a partir de Spinoza e também com Deleuze, diz respeito aos signos que estão a todo momento sendo transmitidos nos encontros.

Pode-se pensar um encontro como violência, colisão, combate, luta. Sempre em movimento, não paramos de nos chocar com as coisas. Os encontros podem ser 
violentos porque produzem mutações. As forças que atravessam os corpos no movimento do encontro resultam em impressões, em marcas, em alterações de estados. As forças agem e produzem efeitos nas superfícies, no espaço em que se exprimem. Há sempre uma afetação importante, uma marca. Spinoza (2011), na Ética, define essa importante relação dos corpos no mundo com os afetos. Ele diz que há uma "força de existir" ("vis existendi") ou uma "potencia de agir" ("potentia agendi") dos corpos que provocam variações na existência. Variações de aumento-diminuição de potência. Deleuze (1978), em aula sobre Spinoza, diz que os afetos são as variações contínuas da força de existir de alguém. Alegria e tristeza são dois polos determinados por Spinoza como variações de aumento e diminuição de potência. Paixões tristes e paixões alegres. Encontros entre os corpos no mundo produzindo afetos que variam a existência. Os afetos são modos de pensamento não-representativos, são forças que existem e agem.

Há em Spinoza uma concepção filosófica que se baseia na materialidade da produção de ideias. É na mistura dos corpos que podem se construir imagens sobre o mundo, percebendo-o e imaginando-o. Nietzsche mais tarde encontrará em Spinoza uma coincidência com seus pontos de vista como a negação da ordem moral universal e a negação do mal. O que existe para Spinoza e Nietzsche é o bom e o mau encontro.

O mal, por exemplo, é na realidade um encontro de um corpo com outro corpo que se mistura mal com ele, no sentido em que o afeta, o modifica de tal maneira que destrói ou ameaça destruir a relação de movimento e repouso que o caracteriza (MACHADO, 2010, p. 75).

Bons encontros podem produzir boas aprendizagens para um professor de historia? Nesta perspectiva não é possível haver um aprendizado, mas aprendizagens possíveis. Deleuze (1978) diz que não há noções abstratas nem fórmulas que sejam boas para o homem em geral. O que há é o poder de ser afetado por algo nos encontros. Eles são sempre individuais, singulares, são sempre graus de potência de cada indivíduo. São as experiências vividas, as maneiras de perceber e imaginar que podem determinar ideias apreendidas.

Não se pode pré-determinar os encontros, eles são sempre ocasionais assim como os efeitos que produzem. A partir de que encontros se produz o pensamento de professor de história? Que efeitos fantásticos e misteriosos eles podem ocasionar em sua

Em Tempo de Histórias

Publicação do Programa de Pós-Graduação em História da Universidade de Brasília (PPGHIS/UnB)

No. 23, Brasília, ago. - dez. 2013

ISSN 2316-1191 
prática? Isto é algo que não se pode pré-estabelecer e pré-determinar. O que pode um documento? O que pode um professor ao encontrar-se com o documento? Que composições estão a ser criadas em narrativas professorais que podem (por que não?) ser fabulosas?

É uma ousadia um professor de história fabular? A produção intelectual de um professor de história na contemporaneidade continua repleta de ideias e representações sobre o passado inscritas em saberes pautados pelo tipo de produção científica que engendra normas e técnicas, métodos e teorias da História. E, como todo saber, considera a realidade vivida pela humanidade como algo existente e verdadeiro e que, portanto, pode ser atingido pelo conhecimento humano. O passado dos homens como algo real é investigado através das pistas sobreviventes e a análise dos documentos confunde-se com o trabalho de um detetive. Sempre incompleto, como um mistério a ser revelado e uma nova verdade a ser descoberta.

Configura um atrevimento propor que o passado possa ser fabulado como expressão de narrativas imaginadas? Constituído de vidas que agiram e padeceram, o passado pode ser pensado como composto de corpos intensos, de forças que se movimentam em um caos. O próprio passado como o caos. Lugar de singularidades préindividuais, lugar ontológico que dá margem para toda a criação. E uma fabulação em história é fazer existir no presente os efeitos dos encontros entre esses corpos. É pensar como uma ação no infinitivo, com inúmeras possibilidades, como acontecimento que se dá segundo as relações de forças que estão a agir nesses encontros. Por isso que não há espaço para a representação prévia à imaginação/fabulação. Não é possível expressar um acontecimento histórico como efeitos dos encontros antes de estes acontecerem. No ato de pensar de um professor de história, múltiplas narrativas são possíveis se admitimos o caos dos corpos em movimento. Corpos de professores e imagensdocumentos a criar novos planos de composição com novas linhas de aprendizagem. Nada há a revelar, mas a imaginar, fabular.

Deleuze (2010), em Proust e os signos, apresenta uma teoria da aprendizagem através dos diferentes signos que se transmitem no encontro com as coisas no mundo. Os signos exercem uma violência que incita novas necessidades: queremos traduzir, decifrar, encontrar sentido na situação concreta que nos tirou a paz. O pensamento, 
portanto, não é algo pacífico, surgido naturalmente de um espírito que busca a verdade. O pensamento é sempre coagido, sempre violentado primeiramente pela força do encontro. A busca da verdade do encontro, do aprendizado que dá sentido à vida, é pensado somente após o choque com os signos. É um trabalho da inteligência. Para Deleuze, "tudo que nos ensina alguma coisa emite signos, todo o ato de aprender é uma interpretação de signos" (DELEUZE, 2010: 04).

A inteligência é movida a pensar como um espetáculo da necessidade. Sem a necessidade o trabalho objetivo da inteligência, como assim pressupunha a filosofia tradicional e as teorias do pensamento ocidental, dá lugar apenas à explicação, à significação explícita na qual se tira pouca coisa: apenas possibilidades abstratas. $\mathrm{Na}$ tradicional filosofia, de linha socrática, a inteligência precede aos encontros. Nesta lógica, primeiro há um espírito pré-disposto na busca da verdade. Esse espírito busca a verdade naturalmente, conscientemente, sendo esta consciência prévia aos encontros. E é este espírito que organizaria os encontros, suscitando-os, provocando-os.

Erramos quando acreditamos nos fatos: só há signos. Erramos quando acreditamos na verdade: só há interpretações. (...) Pois não há leis mecânicas entre as coisas, nem comunicações voluntárias entre os espíritos; tudo é implicado, complicado, tudo é signo, (...). Tudo existe nessas zonas obscuras em que penetramos como em criptas, para aí decifrar hieróglifos e linguagens secretas (DELEUZE, 2010: 86).

É na coação do encontro que sofremos a angústia de não encontrarmos conteúdos explícitos e uma comunicação clara, objetiva. No encontro com os signos o que se emite é implicado e enredado como hieróglifos a serem decifrados. O pensamento é o caminho da decifração. Ele é a formação de ideias que sucedem ao desgosto e à dor. Sem sofrimento não há aprendizado, talvez por isso nos acostumamos a nos afastar do que faz sofrer e do que desacomoda. "Passamos ao largo dos mais belos encontros, nos esquivando dos imperativos que deles emanam: ao aprofundamento dos encontros, preferimos as facilidades das recognições" (DELEUZE, 2010: 26).

\section{Arte e documento}

Em Tempo de Histórias

Publicação do Programa de Pós-Graduação em História da Universidade de Brasília (PPGHIS/UnB)

$N^{\circ} .23$, Brasília, ago. - dez. 2013

ISSN 2316-1191 
A direção do pensamento representativo é acreditar que o signo é o objeto que ele designa. Neste objetivismo se ancora a percepção, a memória voluntária e a inteligência. Há uma tendência da inteligência que deseja a objetividade, a atividade prática, a direção do prazer e da paz. Assim como a percepção acredita que a realidade deve ser vista e observada, a inteligência determina que a mesma deve ser dita e formulada. Esta formulação nos conduz à conversação, à comunicação, incita à amizade. Este é o exercício voluntário e premeditado do pensamento. Na tradição filosófica há o duo: amizade e filosofia onde os indivíduos estão de acordo sobre as significações das coisas, das palavras, das ideias. Há um amor natural e verdadeiro pelo conhecimento. Este amor amigo convoca o pensamento à busca de verdades objetivas e abstratas.

No entanto, Deleuze (2010), através da obra de Marcel Proust (Em busca do tempo perdido), propõe outro duo: amor e arte. Deleuze chama atenção para materialidade do pensamento, da concretude dos encontros e da emissão dos signos. Há um pluralismo nessa emissão, onde os diferentes tipos de signos movimentam o pensar na direção da busca de sentidos. Os encontros não são gratuitos e não nos conferem apenas possibilidades; eles são materiais e geram necessidades corpóreas de verdades. Os signos do amor e da arte valem mais do que a amizade e do que uma obra filosófica. "O que nos violenta é mais rico do que todos os frutos de nossa boa vontade ou de nosso trabalho aplicado; e mais importante que o pensamento é aquilo que faz pensar" (DELEUZE, 2010: 29). As verdades objetivas, que se preocupam da comunicação e da concordância, são amigas do conhecido, do convencional. Nelas não há profundidade, pois nelas não há violência, não há guerra. A amizade quer a paz e por isso não suporta o estrangeiro, o estranho, o vazio e desconhecido.

A clareza das verdades objetivas não satisfaz porque não são encontradas ao acaso e não causam estranheza. Os signos da arte é que são os responsáveis pelo aprendizado eficaz, aquele que dá sentido a todos os demais signos com os quais nos encontramos. São eles que nos apresentam a diferença extratemporal, nos libertam da memória e da inteligência que nos aprisiona no tempo e nos remete à sucessão de passados. Na arte a matéria se espiritualiza e faz refratar a qualidade de um tempo

Em Tempo de Histórias

Publicação do Programa de Pós-Graduação em História da Universidade de Brasília (PPGHIS/UnB)

No. 23, Brasília, ago. - dez. 2013

ISSN 2316-1191 
original, puro, absoluto. A arte nos traz, na sensação de sua presença, dados e figuras complexas que nos enredam em suas tramas e não conseguimos imaginá-las nem decifrá-las facilmente. Nenhum método se aplica na interpretação de uma obra de arte. O que existe são corpos a se exprimir, e dessa linguagem estranha um caminho singular de aprendizado a se produzir.

Daí a importância deste texto conclamar a arte como necessária para o pensamento professoral. Quer-se sair do plano das representações e ideias abstratas e pensar a arte como a grande provocadora de pensamentos que se fazem na relação de corpos a se encontrarem. Como experiências que fabricam novos pensamentos e novos sentidos, as experiências com a arte possibilitam para o pensamento do professor de História novas formas de produzir o passado para além dos métodos e concepções que caracterizam esta área do conhecimento e do ensino. $\mathrm{O}$ que se pretende aqui é poder pensar o passado a partir de uma guerra travada com documentos-obras de arte e concebê-los como signos a causar estranheza, agonia, sofrimento, desolação. É enredarse nos signos da arte e produzir-se, por paixão, como obra de arte, sem modelos nem padrões humanos.

Produzir um pensamento novo no ensino de história passa pela atitude de um professor que também está a se produzir como novidade. Produzindo-se como uma obra de arte, a esculpir o seu pensar, atento ao que está aprendendo e sensível às suas metamorfoses, talvez esse professor possa transmitir algo novo para seus alunos. Um professor em contato com o Fora, que se cria com resultado da dobra, constituindo uma estética da existência, talvez proporcione bons encontros para que os alunos possam aprender com ele. Um aprendizado pela via da arte pode proporcionar novas formas de operar o pensamento e inventar novos procedimentos de construção do saber histórico escolar. Diz respeito à possibilidade de criação de outra via de aprendizagem que se acrescente às já trilhadas pelo ensino de história.

Como um canto de Sereias são os signos que nos enredam. Complicados eles nos envolvem em seu canto inumano e por necessidade desejamos seu significado. Estranhamento, deslumbramento, desespero? Estranhar o mundo ao redor proporciona ao homem o despertar para a suspeita da inumanidade do canto humano e de sua

Em Tempo de Histórias

Publicação do Programa de Pós-Graduação em História da Universidade de Brasília (PPGHIS/UnB)

No. 23, Brasília, ago. - dez. 2013

ISSN 2316-1191 
potência estranha. Esse estranhamento se arrisca no desconhecido, no inexistente no mundo dos humanos. É uma potência terrível e obscura.

Na narrativa de Homero, Odisseu é o herói humano ao encontrar-se com o canto inumano das Sereias. Ela conta da aventura de Odisseu ao resistir ao engano e à mentira. O canto das sereias era um canto insólito e de estranho encantamento; somente os homens do risco e do movimento ousado se atiravam na desventura de segui-lo. Odisseu, o herói humano incomum, feliz e seguro em sua covardia não se deixou seduzir pelo canto das Sereias. No entanto, seu medo e a necessidade de caos capaz de lhe causar estranhamento e trazer-lhe novidade o levou a decidir ouvi-las sem pagar o preço da morte. Ele as venceu como expressão do desejo de dirigir-se ao espetáculo das Sereias, gozar do êxtase de suas presenças, porém não sucumbir às suas mortíferas seduções. Com sua postura de enfrentamento e ao mesmo tempo de entrega ele é a referência ao mundo moderno da razão. Controlar os atos, planejar as estratégias e metas são atitudes da hábil mente humana que Odisseu está a representar. Ele ouve as orientações divinas e somente submete-se a elas mediante análise. Como herói, sabe o que fazer para salvar a si e os outros, sente-se responsável por seu destino e sua vontade é soberana.

Tratar de documentos como obras de arte é tratar de signos enigmáticos; encontrá-los é navegar em águas intranquilas onde se produzem cantos imaginários. É produzir narrativas de acontecimentos não humanos, incorporais, indetermináveis, em devir. É experimentar metamorfoses de corpos que se misturam nos encontros. Pensar filosoficamente é problematizar as experiências da vida, remetendo-as a um movimento de criação estética como um cuidado de si que ultrapassa as noções comuns e as práticas de consciência. Ao voltarmos à Odisseia, podemos pensar ainda: Seria a figura de Odisseu a possibilidade de pensar o que não foi pensado? Seria a Odisséia um documento-arte como possibilidade de livre pensar para além do convencional e do estabelecido? O que Odisseu faz pensar? Em que devires nos faz entrar? Ele não se jogou no abismo do conhecido, da superstição, das velhas certezas e da morte, mas também não fugiu do risco de experimentar a novidade. Teria ele criado uma nova forma de vida, uma forma de fortalecer-se com a experiência do risco?

Em Tempo de Histórias

Publicação do Programa de Pós-Graduação em História da Universidade de Brasília (PPGHIS/UnB)

No. 23, Brasília, ago. - dez. 2013

ISSN 2316-1191 
Tal prática filosófica e artística com documentos-obras de arte em sala de aula podem proliferar novas narrativas. Narrativas que se transmitem como arte (em formas, imagens, histórias, palavras), como sensações que não estão para o tempo cronos, do presente, mas que se mostram em uma linguagem aberta e infinita favorecendo infinitos encontros.

Encontrar um documento como obra de arte no ensino de história pode provocar sensações e produzir novas histórias. Pode permitir a produção de narrativas que se aproximam da fabulação e da invenção de outros passados. Novas narrativas podem tornar mais interessantes e prazerosas as aulas de história movimentando outros sentidos e aguçando outras sensibilidades. Nessa prática é permitida a fuga das experiências de narrativas que se fazem mediante o imperativo do tempo presente e cronológico. A produção de uma narrativa fabulada, que conta com os encontros com a arte, quer enfrentar o caótico e complicado, quer ouvir cantos incompreensíveis e sem referência. E, mais do que isso, quer poder ultrapassá-los, entendê-los e utilizá-los para invenção de novas interpretações da vida.

Ler, escrever, narrar e ensinar História é atualizá-la. É um ato de resistência que está a modificar as diferentes relações de forças que agem entre documentos e professores. É inverter, mudar, modificar o que já existe. É continuar a tornar o campo do saber histórico instável, heterogêneo, singular. Operando consigo na relação com o caos o pensamento emerge como força vital que ativa a própria vida atualizando-se e atualizando o mundo. Desconfiar, problematizar, narrar, contar de outra forma. A vida em devir, em sua estranheza, perigo, surpresa e suspense nunca é a mesma, nunca nos oferece certezas. Nós as criamos como estratégias de sobrevivência, pois as narrativas históricas são formas de nos constituirmos, nos desmancharmos, entrarmos em metamorfoses com o próprio processo histórico. Em seu devir, a História nunca poderá ser previsível, nunca se repetirá. As decisões, as ações, os gestos nunca poderão ser calcados na certeza de que resultarão naquilo que se espera:

A História não é como um castelo, com sua torre central, de onde um sujeito soberano pode visualizá-la em seu devir e pode tomar as decisões que vão mudá-la de rumo. A História é como um labirinto de corredores e portas contíguas, aparentemente todas semelhantes, mas que, dependendo da porta que o sujeito escolhe para abrir, pode estar

Em Tempo de Histórias

Publicação do Programa de Pós-Graduação em História da Universidade de Brasília (PPGHIS/UnB)

No. 23, Brasília, ago. - dez. 2013

ISSN 2316-1191 
provocando um desvio, um deslizamento para um outro porvir (ALBUQUERQUE Júnior, 2007: 73).

Pensar só pode ser um ato inesperado e que parte do indeterminado. O movimento do caos ocasionado pelos encontros passa a ser condição para um pensamento novo. É preciso que haja uma abertura para novos encontros que possibilitem outras linhas de aprendizado à maneira da arte: entrar em contato com essa atmosfera irrespirável e sufocante, porém necessária à mente criadora. Ninguém sabe como alguém aprende ou pensa. No entanto, pensar é um exercício, ainda que sem intenção ou voluntariedade. Ainda que se habite os estratos de saber e se deixe coagir pelas forças do poder, é somente a zona indeterminada do caos que garante o exercício de si. Não se pode medir ou controlar o quanto se deixar abrir para o caótico, mas é possível dispor-se ao movimento da vida e deixar-se abismar pelos encontros.

\section{Arte, cena, pensamento}

Um problema novo em história, levado por um professor aos seus alunos, talvez não seja a apresentação de acontecimentos (eventos, fatos) dos quais ainda não se falou. Um problema em História, capaz de gerar novo pensamento e nova narrativa, talvez seja a apresentação de uma fala inquieta, perturbada com as sensações persistentes dos documentos-obras de arte. Uma tentativa de resposta, uma busca de solução que possa aquietar o mar revolto da curiosidade que os signos da matéria estão a provocar: uma produção potente de narrativa imaginada como prática de livre pensamento.

Uma entrada calma e paciente. Voltada ao norte, sempre como fazia nas manhãs frias de outono; substituía um sorriso no rosto por uma expressão neutra, porque a neutralidade lhe fazia bem, ao que parece. Entrava, então, calma $e$ pacientemente, sem saber bem o que lhe reservava o ambiente daquela sala, irresoluta 73. Uma turma esculpida na borda de uma grande montanha de neve, para quem o mínimo movimento poderia significar uma avalanche. 
Em meio aquele verdadeiro circo, armado ao pé da montanha, ela, ainda calma e pacientemente, dispõe o braçado de livros, cadernos de chamada, caixa de giz, estojo e uma lata de Cola-cola sobre a mesa.

De tudo o que podia acontecer, numa aula programada para acertar em cheio as causas da Segunda Grande Guerra e mostrar por quais razões o Ocidente criou algo como o nazifascismo, foi na lata de cola-cola que a aluna, inquieta e impaciente para qualquer diálogo ou outra forma de relação pedagógica que implicasse sobriedade e atenção, mirou todas as suas forças - forças que lhe fizeram, como num lance de dados, apontar para a lata e dizer: "Professora, porque sempre que queremos um refri pedimos uma coca?".

Em meio a um ainda grande tumulto de entradas e saídas, de passeios pelos corredores, a professora, um pouco atordoada, ainda que sua calma e paciência não tivessem sido abaladas, atônita à pergunta, balança seus longos cachos de um cabelo bem pintado de um branco-grafite, que deixava transparecer sua já avançada idade e igual carreira no magistério, olha a lata de coca-cola e parece se deixar invadir pelas mesmas forças que atravessaram a aluna, quando realizou sua pergunta.

— "Ora, pequena Pat, eu fui, do alto dos meus 49 anos, filha de uma geração Coca-cola”. Ao dizer isso parece que linhas se cruzaram pelas bordas dos seus ditos. Uma linha de saber que marcava claramente seus conceitos sobre a Coca-cola e o mundo capitalista; outra linha que se avizinhava de um vazio de sentido, de uma vontade de fazer algo que lhe fizesse abandonar todos os sentidos possíveis para uma sala de aula, donde o tema era a Segunda Grande Guerra; uma linha de força que lhe preenchia de potência para aguçar a curiosidade da aluna e para movê-la - a professora - a um lugar que ainda nunca teria se arriscado em 25 anos de magistério, ensinando História; outra linha destacava-se desta última constituindo uma professora nova, ou uma não-professora, que ao mesmo tempo se deliciava e se aterrorizava de uma aula que pudesse iniciar e terminar com uma lata de Coca-cola.

Foi então que perguntou a todos, a essa altura, já dispostos ao redor da professora e da mera lata de Coca-cola: "Porque vocês acham que eu bebo Cocacola?" Respostas as mais diversas apareceram, algumas tinham a ver com o gosto, outros com a força da marca, outras com a eficácia do produto em relação a problemas

Em Tempo de Histórias

Publicação do Programa de Pós-Graduação em História da Universidade de Brasília (PPGHIS/UnB) No. 23, Brasília, ago. - dez. 2013

ISSN 2316-1191 
estomacais. Mas, uma resposta deu o tom de toda a discussão que se travou bela, desequilibrada, surpreendente e mítica que se seguiu: "A senhora bebe Coca-cola porque é uma consumidora e quem consome acho que aprende a consumir, pois antes de haver celular, não precisávamos dele”.

E foi assim que aquela lata, anônima como toda a lata de Coca-cola, se fez entrar em um agenciamento que lhe tornou o carro chefe da aula de História. Mais, muito mais e muito menos - que lhe fez entrar num agenciamento que criou novas linhas de expressão para a professora de História e novas linhas de subjetivação para o fazer professoral.

Dali em diante, as aulas de História se tornaram menos submissas a uma imagem de pensamento que vê no modelo o ideal e a base a partir de onde cópias malfeitas se fabricam. Dali em frente, a aula de História tornou-se todos os dias menos aula e mais experiência. Uma experiência aterradora de vida e de morte. Uma experiência que durava sem o norte pré-definido do livro didático, na exposição estafante, na cópia dos exercícios do quadro ou na mal fadada hora da revisão para a prova. De todas as experiências de que se lembra, desde que deixou de ser professora de História, a mais inquietante foi aquela da lata de coca-cola, porque o que se seguiu à intempestiva resposta da aluna, foi uma neutralidade sufocante e estranhamente aberta, porque neutra. Aberta a "eterna novidade do mundo", aberta ao que vem de Fora. Abertura terrífica que dispõe e provoca, a cada aula, uma nova disposição, como presentes que se sucedem desprendendo-se do passado que lhe é possibilidade e condição; como devir que engendra e provoca acontecimentos ${ }^{6}$.

Pensamos em uma escola e em uma sala de aula mais próximas do Caos do que da ordem que seria sua lei. Não em favor de uma desordem, mas de uma desidentificação, de uma desubjetivação, de um estado possível de pensar e de produzir pensamento, nos interstícios, nos intervalos, promovendo alterações e capturando a leveza terrível das durações.

\footnotetext{
${ }^{6}$ A cena descrita é resultado da observação de uma aula de História, em uma turma de oitavo ano, do Ensino Fundamental, na cidade de Porto Alegre, parte de uma pesquisa sobre formas de expressão do ensino de História, deste pesquisador.

Em Tempo de Histórias

Publicação do Programa de Pós-Graduação em História da Universidade de Brasília (PPGHIS/UnB)

No. 23, Brasília, ago. - dez. 2013

ISSN 2316-1191
} 


\section{Referências Bibliográficas}

ALBUQUERQUE Júnior, Durval M. Historia: a arte de inventar o passado - Ensaios de teoria de História. Bauru: Edusc, 2007.

BITTENCOURT, Circe (org.). O Saber Histórico na Sala de Aula. Coleção Repensando o Ensino. Editora Contexto (Editora Pinsky Ltda.). São Paulo, 2004.

DELEUZE, Gilles. Bergsonismo. Tradução de Luiz Orlandi. São Paulo: Ed. 34, 1999.

DELEUZE, Gilles. Foucault. Tradução Claudia Sant'Anna Martins. 1. Ed. São Paulo: Brasiliense, 1988.

DELEUZE, Gilles. Proust e os signos. Tradução de Antonio Carlos Piquet e Roberto Machado. Rio de Janeiro: Forense Universitária, 2010

DELEUZE, Gilles. Sobre Spinoza. Cours Vincennes - 24/01/1978. Tradução de Francisco Traverso Fuchs. http://www.webdeleuze.com/php/texte.php?cle=194\&groupe=Spinoza\&langue=5 $\quad($ acesso em setembro de 2011).

FEBVRE, Lucien. Apud LE GOFF, Jacques. História e Memória. Tradução de Bernardo Leitão. São Paulo. Campinas, Editora da Unicamp, 1992.

FOUCAULT, Michel. A hermenêutica do sujeito. Tradução de Márcio Alves da Fonseca e Salma Tannus Muchail. São Paulo: Martins Fontes, 2004.

FOUCAULT, Michel. O pensamento do exterior. In: Ditos e Escritos III. Estética: Literatura e Pintura, Música e Cinema. Tradução Inês Autran Dourado Barbosa. 2. ed. Rio de Janeiro: Forense Universitária, 2009.

MACHADO, Roberto. Deleuze, a arte e a filosofia. $2^{\mathrm{a}}$ ed. Rio de Janeiro: Jorge Zahar Ed., 2010. p. 75 PELBART, Peter Pál. Da clausura do Fora ao Fora da clausura: Loucura e Desrazão. São Paulo. Brasiliense. 1989.

PEREIRA, Nilton Mullet; SEFFNER, Fernando. O que pode o ensino de História? Sobre o uso de fontes na sala de aula. Anos 90, Porto Alegre, v.15, n.28, p.113-128, dez.2008.

SCHIMIDT, Maria Auxiliadora \& CAINELLI, Marlene. Ensinar História. São Paulo. Scipione, 2004. SPINOZA, Benedictus de. Ética. Tradução de Tomaz Tadeu da Silva. $2^{a}$ ed. Belo Horizonte: Ed. Autêntica, 2011. 